\title{
Research and Innovation in Agricultural Engineering in a University in KwaZulu-Natal
}

\author{
Dr. Kehdinga George Fomunyam \\ Teaching and Learning Development Center, Mangosuthu University of Technology, Durban, South Africa.
}

\begin{abstract}
With high incidences of population growth, increasing food deficits, soaring demands for food and the various environmental challenges has necessitated that agriculture and food production scale up to become issue of international, political, policy and research agenda. There are various projections that the global population might increase to 9billion by 2050 and such increase will be prominent in Asia, Latin America and in Sub-Saharan Africa. One of the greatest concern is that to meet the increasing need for food amongst the population, at least $60 \%$ increase in food production is necessary to need the need of the population. Research and innovation in agricultural engineering is crucial in overcoming the major challenges caused by global changes taking place now. This paper is aimed at guiding policy decisions in education and it seeks to provide an investigation into research and innovation in agricultural engineering in a university in KwaZulu-Natal. This study explored the nature of research and innovation in a university in KwaZulu-Natal. To provide answers to the research questions, a literature review was carried out to locate researches made in agricultural engineering in a university in KwaZulu-Natal between year 1988 to 2016. Research and innovation in agricultural engineering is categorized along four dimensions which are optimizing and Regulating combustion in compression ignition engines, energy use and Post-harvest management of sugarcane, Small holder Irrigation and small scale water infrastructure in South Africa, Climate issues and the extension need of smallholder farmers in South Africa. This study recommended that there is a need to have a change to research and innovation in agricultural engineering in a university in KwaZulu-Natal due to changing context and conduct of events. With the sustainable development goals and many challenging issues to deal with, there should be a focus on fourth industrial revolution and its application to agricultural engineering, climate change issues, gender issues in agricultural engineering, food security and sustainability of food crop production etc.
\end{abstract}

Keywords: Research, innovation, agricultural engineering, agriculture, engineering

\section{INTRODUCTION}

With high incidences of population growth, increasing food deficits, soaring demands for food and the various environmental challenges has necessitated that agriculture and food production scale up to become issue of international, political, policy and research agenda. According to FAO Statistics (2016), there are various projections that the global population might increase to 9billion by 2050 and such increase will be prominent in Asia, Latin America and in SubSaharan Africa. One of the greatest concern is that to meet the increasing need for food amongst the population, at least $60 \%$ increase in food production is necessary to need the need of the population (Blackmore, 2012: Wilson, 2013). With this staggering food issues, there is also the scourge of climate change and population growth on agriculture and the global environment in the years ahead which will be more grievous and challenging.

Agriculture has been a succor to the worlds problem and it is normally driven by engineering interventions which involves interaction between plants, animals and mechanical devices. As humans develop and expanded over the years, there was the need to develop the tools necessary for meeting their basic survival needs which led to the development of simple mechanical devices powered by man and draught animals (Adekoya, 2014). This over the years has increased and there are now sophisticated technology devices necessary for planting, harvesting, handling and processing food for mans need.

Research and innovation in agricultural engineering is crucial in overcoming the major challenges caused by global changes taking place now. Evidences from various works done by Adam Smith (1776): Schumpeter (1934), Solow (1975) have shown that there is a strong relationship between research, innovation and economic growth. With the population increasing and the constraint posed by climate change, there is a need for research and innovation in agricultural engineering. Consequently, this study will consider research and innovation in a university in KwaZulu-Natal and shed light on agricultural engineering, nature of research and innovation the same university and the challenges and obstacles in agricultural engineering in the university.

\section{BACKGROUND}

Agricultural engineering is the use of engineering knowledge and principles to solve agricultural problems which is aimed at production and delivery of food and fiber to under conducive conditions without jeopardizing the environment (Harry et al, 2000: Senzanje, 2003). With various changes happening recently coupled with the increasing global 
population and a higher number of people to feed, there is a need to have better approaches to production and delivery of food to the world. What agricultural engineering does is to infuse the apparatus of technology to better crop and animal production.

From history, agricultural engineering as a profession dates back to around 1907 and it has been reputed to be as old as most engineering disciplines (Cuello, 2004). With the need for human survival and meet their basic needs, there was the need to have a better approach to agricultural production which will infuse the use of mechanical devices. This has helped to contribute to development of mankind with agricultural mechanization being one of the 20 greatest engineering inventions of the $20^{\text {th }}$ century (Inside ASAE, 2000). The various feats in agricultural engineering recorded in the $20^{\text {th }}$ century was attributed to the agricultural engineers that were at play then. What helped with the expertise of early engineers was predicated on sound and robust training and education programme. The trainings of agricultural engineers were characterized by a thorough theoretical and practical training which made them productive in their venture. The imperative of agricultural engineering is manifested in it being one of the most effective and powerful tools of development in the last century which has helped improved industrialization significantly (Cuelo, 2002).

The most applicable definition of innovation in the R\& D perspective is given by Bean and Radford (2002) and innovation was defined as the economically prosperous application of invention and invention was seen as a solution to problems. It was revealed by Bennert (2008) that research is important in converting money into knowledge while innovation converts knowledge into money. The entire process that converts money to knowledge is a complicated which starts from critical inquiry about particular problems to proffer solution. Taking a bit of an idea and trying to learn about it to make it better and in this process, money, time and other resources are expended. Innovation works on knowledge that has been produced from research and converts it into money. Seeking new ways to make things better has the capability to improve processes and production which ensures that knowledge is converted into money. In agriculture, innovation involves all processes associated with production, distribution, adaptation, and the application of new technical, institutional, organizational and managerial knowledge for service delivery (Hall, Mytelka and Oyeyinka, 2005)

According to Blackswan (2010) a three legged illustration shows the innovation process and the role of research. The three pivotal elements to the innovation process are

1. Education or knowledge generated from basic and strategic research

2. An ability to convert the knowledge into physical products made possible through strategic, applied and adaptive research

3. The ability to propagate the ideas to the world through commercialization, communication and service delivery.

From the three points made above, it is important to note that research is important in the innovation process. From basic and strategic research stems knowledge critical to develop on a product or service. Having in-depth knowledge about any particular concept, service or product will help in having full grasp of what you intend to develop. The second step critical to the innovation process is the ability to convert the knowledge into physical products made possible through strategic, applied and adaptive research. Knowledge gained from basic and strategic research is not enough in the innovation process. Knowledge is useless until it is applied to solve a particular problem which necessitates that the knowledge gained from basic and strategic research is converted into tangible commodities. Furthermore, knowledge is starved if it is not propagated and for the knowledge to have its full import in the innovation process, it must be disseminated to the recipients or those that will find it useful and the general public. Research and innovation is a continuous process of discovery and rediscovery, fueled by the desire to proffer solution to problems in the society. The end of the process is the recipients and they might include the government, society, institutions, individuals etc.

AIM

This research is aimed at guiding policy decisions in education and it seeks to provide an investigation into research and innovation in agricultural engineering in a university in KwaZulu-Natal. This study explored the nature of research and innovation in a university in KwaZulu-Natal.

\section{METHODOLOGY}

To provide answers to the research questions, a systematic literature review was carried out to locate researches made in agricultural engineering in a university in KwaZulu-Natal between year 1988 to 2016 . South Africa has been a country that ranks highly among other African countries in terms of agricultural engineering but there is a need to look into research and innovations in a university in KwaZulu-Natal. Therefore, this review sought to shed light the various researches made in agricultural engineering and to make recommendations on the future of research and innovation in a university in KwaZulu-Natal. Output of this research is meant to provide a template of reference for educators, policy makers critical to the educational sector and research to guide decisions for the future of education.

\section{Inclusion/exclusion criteria}

Two inclusion criteria were considered to select relevant studies.

(1) thesis and dissertation published in department of agricultural engineering in a university in KwaZuluNatal between 1988 to 2016

(2) thesis and dissertation that were accessible at the time this research was conducted.

\section{Data and extraction}

Approach to this study considered thesis and dissertation published between 1988 to 2016 
International Journal of Engineering Research and Technology. ISSN 0974-3154, Volume 13, Number 7 (2020), pp. 1497-1503

(C) International Research Publication House. https://dx.doi.org/10.37624/IJERT/13.7.2020.1497-1503

\section{Exploring research and innovation in a university in KwaZulu-Natal}

Research and innovation in agricultural engineering is categorized along four dimensions which are

\section{Optimizing and Regulating combustion in compression ignition engines}

Various researches were carried out on optimizing and regulating combustion in compression ignition engines. Alan Christopher Hansen (1989) explored a diagnostic quasidimensional model of heat transfer and combustion in compression-ignition engines. The study was aimed at developing a combustion model that was less empirically based than the existing zero-dimensional models for use in evaluating the combustion and resulting thermal stresses generated by alternative fuels in diesel engines. In his research, tests were carried out on a naturally aspirated ADE 236 engine involving the measurement of cylinder pressure and heat flux at a single point. Motored engine data were used to verify the convective heat transfer rates and to ascertain the effects of soot deposition on the heat flux probe. Close correlation between predicted and measured heat flux was achieved after accounting for the effects of chamber geometry at the probe site. It was revealed that the fire engine tests showed that the two zone combustion model was providing plausible trends in the burnt and unburnt zone temperatures and that the model generated combined heat transfer rate which were credible not only on a global basis but also in terms of point predictions in the combustion chambers.

Peter William Liversedge Lyne (1991) explored the automated processor for optimizing tractor operation. The study aimed at developing and evaluating a control system using the single wheel traction research vehicle at the USDA'S national soil dynamics laboratory in Auburn, Alabama, USA. In the study, a computer management system was developed to control dynamic load, net traction and inflation pressure of the test tyre. During a simulated field operation, the system was programmed to cycle the tyre over its operating range of dynamic load and inflation pressure while monitoring tractive efficiency. Evaluation showed that within the operating range of the tyre, tractive efficiency varied considerably with dynamic load, inflation pressure, net traction and spoil condition. The result indicated that a considerable advantage could be obtained by using an arrangement of a tractor.

Paul Anthony Nordengen (2013) studied the development and evaluation of a performance-based standards approach for regulating the use of heavy vehicles in South Africa. The research aimed at applying, refining and demonstrating an alternative approach to the design and operation of heavy vehicles in South Africa. Under a performance based system(PBS) approach, performance measures such as low speed swept path, reward amplification, load transfer ratio and his speed off tracking are utilized to specify the performance required from vehicles. Result shows a significant improvement in payload control and fuel efficiency of the PS vehicles compared with the baseline vehicles. This also resulted in a reduction in $\mathrm{CO}_{2}$ emission per ton $\mathrm{km}$.
Andrew Bruce Taylor. (1989) researched into combustion stress in compression-ignition engines. The study investigated the relative role of combustion variables in the failure of engines. The research required the development of a complete engine research facility as well as some specialized transducers. Fast response surface thermocouples were designed and constructed in order to monitor transient surface temperature. The results successfully identified the causes of combustion related engine failures. The primary failure of engine failure was found to be thermal loading. The principal cause of any variation in thermal loading and thus engine durability was maximum cylinder pressure.

\section{Energy use and Post-harvest management of sugarcane}

There were various researches on sugarcane and its postharvest management in a university in KwaZulu-Natal. Kadwa (2014) researched into the comprehensive qualitative and quantitative assessment of harvesting and other sugarcane supply chain disruptions within the Eston Mill Supply area. the study considered the factors which cause inconsistencies in sugarcane supply chains and the strategies implemented for improvement. The research involved five main aims, a novice qualitative diagnostic analysis of the Eston sugar cane system, secondly, based on the diagnostic analysis, a model that predicts and quantifies the factors which influence daily crush rate disruption at Eston was developed, validated and verified, thirdly, the extent of the pay-weekend problem area was systematically estimated in terms of frequency, variability and predictability. Fourthly, the cost of cutter absenteeism was conservatively quantified, lastly, a case study was carried out. Findings from the study revealed that the model captures $64 \%$ of the variation observed in daily crush rates. An economic analysis estimated the costs associated with cutter absenteeism to be approximately R1.3million per season for the Eston region. The alternative harvesting system, case-study solution was found to be risky.

MS Sibomana (2014) did an assessment of the feasibility of quality indicators for the post-harvest deterioration of sugar cane (Saccharum officinarum L). the study evaluated the postharvest quality management systems and measurements in the South African sugar cane and fresh produce industries. In the research, an empirical study of standard sugar industry cane quality parameters was performed. Sugarcane quality parameters measured at the Felixton mill were analyzed per ward using quality control charts and non-parametric statistical approaches.

DN Boote (2014). studied the development and assessment of a direct energy calculator for use in sugar cane production. The study aimed at measures which needed to be taken to reduce EU and increase EU efficiencies of on-farm operations. The study developed an energy calculator to estimate energy use (EU) in sugarcane production in South Africa. The result generated by the calculator highlight areas of high energy intensity and low

energy efficiencies at three different levels of detail. Based on these results, changes in management practices and technological improvement can be made to reduce EU and Carbon footprints. 
EPG Jenkins. (2014) worked on modelling sugar cane quality in the context of mill scale supply chain logistics. In the study, LOMZI was adapted and expanded to allow the LOMS for any MSA in south Africa to be investigated. a predictive MS scale cane quality model was developed, based on recent weather condition and a mechanistic understanding of sugar cane quality. A total of 98mill-specific coefficients were calibrated from historic milling data and for model demonstration purposes, the quality model was applied at two mills, namely Sezela and Umfolozi. A useful method to estimate the average burn/cut to crush delay for a MSA was also identified.

B Rees (2015) researched on evaluation of systems to harvest, process and transport sugarcane biomass. The study examined different residue recovery methods which were incorporated in a model. A costing model was adopted and further developed with the objective of estimating the cost incurred by residue collection and transport. The different residue recovery routes which were identified in the literature review, were incorporated into the model. It was found out that the cost of residue recovery i.e the cost of the residue was less than that of coal and thus, these routes are potentially economically beneficial for the mill.

GLN Boote (2011) studied the issues pertaining to cane supply reliability and stockpiling at the Umfolozi sugar millmodel development and application. The study aimed at ensuring that mills operate with optimum efficiency. In the study, a stochastic model was created to simulate the effectiveness of an enlarged cane stockpile if it were maintained on the current tram sliding outside the mill and were crushed when wet water prevented further harvesting. Result showed that the stockpile was effective in reducing the length of milling season and the number of cane stops.

\section{Small holder Irrigation and small scale water infrastructure in South Africa}

Taziva Gomo. (2012) assessed the performance of smallholder irrigation in South Africa and opportunities for deriving best management practices. The study assessed the technical performance of the Mooi River irrigation scheme (MRIS) from the technical managers and the famers point of view. Three performance indicators related to water supply and delivery: conveyance efficiency, dependability of irrigation intervals between water application and relative irrigation supply and two agricultural performance indicators namely output per unit irrigation supply and output per unit water consumed, were assessed during the spring and summer of 2010/2011 season. The result showed an overall scheme conveyance efficiency of $86.4 \%$, a maximum dependability of irrigation intervals between water applications of 2.57 in spring and a scheme relative irrigation supply of 1.48.

RA Johnson. (2018). Improving rainfall erosivity estimates for the design of soil conservation structures in South Africa. The study applied erosivity density approach in order to calculate rainfall erosivity. Owing to the paucity of suitable short duration rainfall data, a second approach was attempted in which rainfall erosivity calculated from the short duration data was related to daily rainfall characteristic. The erosivity density method showed lower rainfall erosivity values than the daily data method. It also produced a much lower maximum annual rainfall erosivity than the daily data method.

David Findlay Scott. (1994). Studied the hydrological effects of fire in South African catchments. The study examined stream-flow and storm-flow in four small catchments which were analyzed by the paired catchment method for a response to fire. Two of the catchments were vegetated with over mature Fynbos, one was afforested to Pinus radata and the fourth to Eucalyptus sastigata. One of the fynbos catchments were burned in a prescribed fire in the late dry season. The sother catchment burned in wildfires. It was revealed that neither of the two catchments showed a change in storm flows. Annual total flow increases of around $16 \%$ were in line with predictions, being related to the reductions in transpiration and interception.

Mark Clifford Dent. (1988) studied crop water requirements for irrigation planning in South Africa. The study was aimed at providing information on soil moisture. The study produced a detailed delimitation of 712 zones throughout Southern Africa, of more or less homogenous climate and by providing estimates of crop water requirements under dryland and irrigated conditions in each zone. The study produced a map of Southern Africa in which 712 homogenous climate zones are depicted. For each of these zones, four pages of computer printout were produced. These pages contain the results of the crop water requirements study for irrigated conditions and the crop water requirement deficit, runoff and an index of stress days for a range of crops, soils and planting dates under dryland conditions.

Nelile Ngubo. (2016) studied the effect of bioslurry, grass clippings and pumpkin live mulch on soil water content and maize production. The study evaluated the effect of bioslurry mulch compared to other selected mulches on soil moisture conservation in relation to maize yield. An on farm experiment was conducted at Okhombe in the Upper Thukela, an on station experiment conducted at the KwaZulu-Natal, Pietermaritzburg and a pot experiment carried out under controlled conditions in a growth chamber. The experiment was conducted as a single factor in a randomized complete block design (RCBD) and the treatments were replicated four times giving a total of 16 experimental units $(5 \mathrm{~m} * 5 \mathrm{mplots})$. The result of the soil water content measured using a Hydrosense II probe system showed that soil water content was significantly higher $(21.55 \%, \mathrm{P}>0.05)$ from the grass clippings mulch $(19.88 \%)$ and pumpkin live mulch treatment $(21.30 \%)$. The largest leaf area $(154.9 \mathrm{~cm} 2)$ was recorded from the plots mulched with bioslurry compared to other mulches.

Mark John Summerton (1995) explored process and modelling studies in forest hydrology. The research developed an enhanced ACRU forest decision support system (FDDS) now called the ACRU forest model and it was proposed as a tool for modelling forest hydrological impact on water resources. A literature survey was conducted and two fieldworks at two locations which are forest irrigation trials at Mkuze in Northern Kwazulu-Natal and at forest site preparation trials near Ugie in the Eastern cape. Findings of research revealed that large tree water use potentials are possible if water is not limiting although, a water supply 
threshold exists at about $1400 \mathrm{~mm} /$ annum above which diminishing growth returns occur.

DC Sambo (2015). Assessment of the performance of small scale water infrastructure (SWI) for multiple uses in Nebo Plateau, Sekhukhune district, South Africa. The study assessed the performance of SWI in the study area by identifying types, distribution, ownership, water use and status using a survey tool. Rapid rural appraisal was used to collect data in Nebo plateau and questionnaires and key informant interview were conducted. The study found 202 SWI which comprises of unequipped boreholes (59\%), equipped boreholes and hand pumps (10\%), electric driven pumps (6\%), diesel driven pumps (1\%), windmills (4\%), small reservoirs $(11 \%)$. The overall water use was $65 \%$ SUS, $22 \%$ MUS, $13 \%$ other. It was also revealed that the government owned $54 \%$ of the SWI, communities owned $22 \%$, private sector owned $11 \%$, schools owned $2 \%$.

Climate issues and the extension need of smallholder farmers in South Africa.

Zafezeka Mbali Ziikhali. (2016) researched on meeting the extension needs of smallholder farmers; The climate information gap in the public agricultural extension and advisory services in Limpopo, South Africa. The study examined the gap in climate information within public agricultural extension and advisory services in Limpopo. The study employed the use of a semi-structured questionnaire on 90 public extension officers selected through purposive sampling. The data was analyzed using IBM SPSS. Content analysis was used for analyzing qualitative data. Majority of the participants were males between ages 31-59 and they possess B. Tech qualifications. Women extension agent were more educated than the males and extension officer's awareness off climate change was average. It was also reported that educational level had an influence on exposure to climate education.

Ellen L Thipe (2014). Comparative analysis of two greenhouse microclimates in the sub-humid climate of South Africa. The study analyzed temperature and relative humidity of two types of greenhouse tunnels which are the fan-pad evaporatively cooled (FPVT) and the open-ended naturally ventilated tunnels (NVT). The study examined the effect of microclimate on crop growth, yield and quality, using tomatoes in the summer months and lettuce in winter. It was found out that the daytime temperature was lower in the FPVT than the NVT during both summer and winter periods. Night temperatures were not significantly different $(\mathrm{p}>0.05)$. The RH was higher in the FPVT than in the NVT both during the day and night.

\section{FINDINGS FROM THE STUDY}

It was found out from the themes emerging from the data collected from the thesis and dissertation in agricultural engineering that research was delineated around four broad categories. This implies that research and innovation in agricultural engineering in a university in KwaZulu-Natal was around four broad categories as categorized in this study. The research and innovation in agricultural engineering in a university in KwaZulu-Natal were narrow in focus. Research at all clime must be broad and multi-faceted giving more opportunity for variation. This will ensure that all issues imperative to development and agricultural production are taken into consideration.

Also, it was found out that the researches were not tailored to meet up with current realities and also lack the capability to contribute to the sustainable development goals. It is noteworthy to bear in mind that there are emerging areas to research into which has the potential to tackle current challenges. Some of these include climate change, sustainability, the fourth industrial revolution and the technologies emerging from it, food security etc. with the global population increasing at a geometric pace, it portends more challenges on the environment and as the climate is changing, the volume of environmental elements critical to agricultural production has dwindled also. So, new thematic areas that can factor this changes into perspective, ensure new ways of managing and conserving the environment, encourage production with minimal resources must be encouraged.

\section{DISCUSSION OF FINDINGS}

As revealed in the findings of the study that there are four themes emerging from the various thesis and dissertation in agricultural engineering in a university in KwaZulu-Natal. It becomes important to shed light on each theme. The first theme is optimizing and regulating combustion in compression ignition engines. As an energy conversion device, the internal combustion engine has immense benefit to the society and it has the ability to provide economically viable and reliable power to stationary and moving automobiles and this has resulted to mass production of the internal combustion engine. Evaluation of combustion stress, heat transfer and combustion in compression-ignition engines, optimizing tractor operation, regulation of heavy traction vehicles was the focus of this theme.

It was also found out from the study that sugarcane was a crop that has been focused on in agricultural engineering in a university in KwaZulu-Natal and various researches have been carried out on it. Apart from it being a fruit, more focus was placed on energy use and post-harvest management of sugar cane. Sugarcane has a variety of technical and production characteristics which defines its quality and affect its processing. There is a need for studies on post-harvest management of sugar cane because the sugar accumulated in the stem of the sugarcane shows a balance between synthesis of sugar and its utilization. A well ripened and harvested sugarcane crop might lose its sweetness and sugar within a few days after harvest and this gets worsen as a result of high ambient temperature, pre-harvest burning, injuries due to transportation and microbial infestation. Also, stalling for some periods after harvesting results in considerable loss in the weight of the cane as a result of loss of moisture. This has further consequences on the crop such as reduction in recoverable sugar, reduction in mill and boiling house capacities, loss of sugar in molasses and other forms of deterioration. 
As a result of the water deficit which is attributable to low and erratic rainfall, high evaporation rate that affects dryland crop production necessitates smallholder irrigation. This was also one of the themes emerging from researches in agricultural engineering in a university in KwaZulu-Natal. It was found out that irrigated agriculture serves as a suitable alternative to these negative conditions. Irrigation is the artificial application of water to land for the purpose of enhancing production. It offers immense benefit for humanity as production can go all year round and helps in ensuring availability of food throughout the year. Evidences from available sources revealed that in 2010, there were 302 smallholder irrigation schemes with a combined command area of 47667 hectares in South Africa.

Climate issues have always been a thing to grapple with since and its effect is more noticeable nowadays. It is noteworthy to bear in mind that the environmental conditions have changed as a result of the emission of greenhouse gases into the atmosphere. This has damning consequences for living and non-living elements in the environment.

\section{CONCLUSION}

This research has looked into research and innovation in agricultural engineering in a university in KwaZulu-Natal. Evidences from various thesis and dissertation between 1988 to 2016 were used in this study. From the thesis and dissertation, it was found out that research and innovation were delineated around four categories which were expatiated on in this study.

\section{RECOMMENDATIONS FOR FUTURE WORKS}

This paper has considered research and innovation in agricultural engineering in a university in KwaZulu-Natal and thesis and dissertation from the institution was used in supporting the study. There is a need to have a change to research and innovation in agricultural engineering in a university in KwaZulu-Natal due to changing context and conduct of events. With the sustainable development goals and many challenging issues to deal with, there should be a focus on fourth industrial revolution and its application to agricultural engineering, climate change issues, gender issues in agricultural engineering, food security and sustainability of food crop production etc.

\section{REFERENCES}

Adekoya, L. O. 2014. Man Minus Machine Equals a Labourer. Ile Ife, Nigeria: 267th Inaugural Lecture Delivered Department of Mechanical Engineering, Faculty of Technology, Obafemi Awolowo University.

Alan Christopher Hansen (1989). A diagnostic quasidimensional model of heat transfers and combustion in compression-ignition engines. Unpublished $\mathrm{PhD}$ dissertation University of Natal.
Andrew Bruce Taylor. (1989). Combustion stress in compression-ignition engines. Unpublished $\mathrm{PhD}$ dissertation. University of Natal

B Rees (2015). Evaluation of systems to harvest, process and transport sugarcane biomass. Unpublished MSc thesis. University of KwaZulu-Natal.

Bennett, A., 2008. Up-scaling Knowledge and Innovation for Development. Paper presented at the International Food Policy Research Institute conference, "Advancing Agriculture in Developing Countries through Knowledge and Innovation," Addis Ababa, Ethiopia, April 7, 2008.

Blackmore, S. 2012. Precision Farming - Agricultural Engineering in the 21st Century. Available at: https://cdn.harperadams.ac.uk/document/page/121207Precision-Farming-and-Agricultural-Engineering-for 952937.pdf. Accessed 20 October 2017.

Blackswan. 2010. The 3-Legged Stool of Innovation: Driving Innovation Success. Blackswan Whitepaper Series.

Cuelo, J. L. (2002): Agricultural engineering and international development in the $3^{\text {rd }}$ millennium. Foreword to "A special ASAE/CIGR session held at the 2002 joint ASAE International Meeting and CIGR World Congress" on 30th July 2002 in Chicago,Illinois, USA

David Findlay Scott. (1994). The hydrological effects of fire in South African catchments. Unpublished $\mathrm{PhD}$ dissertation. University of Natal.

DC Sambo (2015). Assessment of the performance of small scale water infrastructure (SWI) for multiple uses in Nebo Plateau, Sekhukhune district, South Africa. Unpublished MSc Thesis. University of Kwazulu-Natal

DN Boote (2014). The development and assessment of a direct energy calculator for use in sugar cane production. Unpublished MSc thesis. University of KwaZulu-Natal.

Ellen L Thipe (2014). Comparative analysis of two greenhouse microclimates in the sub-humid climate of South Africa. Unpublished MSc Thesis. University of KwaZulu-Natal

EPG Jenkins. (2014). Modelling sugar cane quality in the context of mill scale supply chain logistics. Unpublishhed MscEng Thesis. University of KwaZulu-Natal

FAO Statistics. 2016. FAO Statistics. Available at: http://www.fao.org/statistics/en/. Accessed 20 November 2016.

GLN Boote (2011). Issues pertaining to cane supply reliability and stockpiling at the Umfolozi sugar millmodel development and application. Unpublished MSc thesis. University of Kwazulu-Natal 
International Journal of Engineering Research and Technology. ISSN 0974-3154, Volume 13, Number 7 (2020), pp. 1497-1503

(C) International Research Publication House. https://dx.doi.org/10.37624/IJERT/13.7.2020.1497-1503

Hall, A., L. Mytelka, and B. Oyeyinka. 2005. ISs: Implications for Agricultural Policy and Practice. ILCA Brief 2. Addis Ababa: International Livestock Centre for Africa.

Inside ASAE: Agricultural mechanization named among top 20 engineering achievements, Resource, 7(4), April 2000, p. 17.

J. L. Cuello, The descent of biological engineering. http://ag.arizona.edu/ABE/People/Faculty_Homepages/Cu ellos_Homepage/Thoughts/ (2004).

L. U. Opara, Outlook for agricultural engineering education and research and prospects for developing countries, Outlook on Agriculture, 33(2). 2004, pp. $101 \pm 111$

M Kadwa. (2014). A comprehensive qualitative and quantitative assessment of harvesting and other sugarcane supply chain disruptions within the Eston Mill Supply area. Unpublished $\mathrm{PhD}$ dissertation. University of KwaZulu-Natal.

Mark Clifford Dent. (1988). crop water requirements for irrigation planning in South Africa. Unpublished $\mathrm{PhD}$ dissertation. University of Natal

Mark John Summerton (1995). Process and modelling studies in forest hydrology. Unpublished MSc Thesis. University of Natal

MS Sibomana (2014). An assessment of the feasibility of quality indicators for the post-harvest deterioration of Sugarcane (Saccharum officinarum L). unpublished $\mathrm{PhD}$ dissertation. University of KwaZulu-Natal.

Nelile Ngubo. (2016). The effect of bioslurry, grass clippings and pumpkin live mulch on soil water content and maize production. Unpublished MSc thesis. University of KwaZulu-Natal

Paul Anthony Nordengen (2013). The development and evaluation of a performance-based standards approach for regulating the use of heavy vehicles in South Africa. Unpublished $\mathrm{PhD}$ dissertation. University of KwaZuluNatal

Peter William Liversedge Lyne (1991). Automated processor for optimizing tractor operation. Unpublished $\mathrm{PhD}$ dissertation. University of Natal

Senzanje, A, (2003), 'Problems faced and Advances made by Agricultural Engineers in Southern and Eastern Africa.' Agricultural Engineering International: the CIGR Journal of Scientific Research and Development. Vol. V, March 2003.

Taziva Gomo. (2012). Assessing the performance of smallholder irrigation in South Africa and opportunities for deriving best management practices. Unpublished MSc Thesis. University of KwaZulu-Natal
Wilson, C. L. 2013. Establishment of a World Food Preservation Center: concept, need and opportunity. Journal of Postharvest Technology, 1(1): 1-7.

Zafezeka Mbali Ziikhali. (2016). Meeting the extension needs of smallholder farmers; The climate information gap in the public agricultural extension and advisory services in Limpopo, South Africa. Unpublished MSc Thesis. University of KwaZulu-Natal 